\title{
Sub-national Estimates of Human Capital Indicators: Localizing Investments for the Demographic Dividend
}

\author{
Sainan Zhanga, Edilberto Loaiza ${ }^{b}$, and Rachel Snowc \\ ${ }^{a} A$ United Nations Population Fund, TD/PDB, United Nations Population Fund \\ 605 3rd Ave. New York, NY, USA. \\ szhang@unfpa.org
}

\section{Abstract}

Declining fertility in many countries of Africa and Asia combined with a growing proportion of people of working age is opening potential for a demographic dividend in many countries. A demographic dividend is defined as the economic benefit that can arise when a population has a relatively large proportion of working age people coupled with a history of effective human capital investment. Adopting the Global Agenda Council policy framework on achieving a demographic dividend, this research has developed a method for measuring human capital needs at the national and sub-national level by using a "demographic dividend index". By mapping the dependency ratios and human capital indicators of the districts of Nepal, this paper illustrates an innovative descriptive method for showing policy makers the priority geographic areas for investments that will maximize prospects for a demographic dividend. Besides the identification of priority districts using the index, the research visualizes the spatial distribution of each indicator, as well as further disaggregates the indicators by urban/rural and gender. This disaggregated data is helpful in identifying the key issues within districts, as well as reducing urban/rural and gender inequality in each district level. The findings provide important insights pertaining to place of residence and gender issues.

Key Words: demographic dividend, human capital, empowerment, education, employment

\section{Introduction}

Many countries are experiencing declines in fertility and mortality and have a large proportion of people at working age today. This demographic transition leads to fewer dependents and a decrease in the dependency ratio, thus opening the potential for a demographic dividend (UNFPA, 2014a). A demographic dividend is the economic benefit that can arise when a population has a relatively large proportion of working age people, coupled with effective human capital investments in young people, to ensure high levels of decent employment.

The population of young people aged 10-24 has reached 1.8 billion worldwide, and some of the largest cohorts of young people reside in sub-Saharan African and southern and western Asian countries (UNFPA, 2014a). This in particular arouses attention and calls for reaping a demographic dividend leveraging the potential of young people. Case studies on harnessing a demographic dividend have been carried out widely in these regions (UNFPA, 2015b; FAD and $W B, 2015)$ and in individual countries (UNFPA, 2014b; UNFPA, 2015a).

Existing research on the demographic dividend has been notably lacking an emphasis on human rights or the impact of social inequality on reaping economic gains. To address these gaps of analysis on the demographic dividend, the United Nations Population Fund (UNFPA) has adopted the framework of the World Economic Forum Global Agenda Council (WEF/GAC) on the Demographic Dividend (2014), which emphasizes the importance of transformational and multi-sector investment in rights-based human capital for countries to harness the potential economic gains offered by a favorable age structure ("A 3E Policy Framework to Reap the Demographic Dividend: Empower, Educate, Employ", 2015). The WEF/GAC identifies three areas of investment (the three "E" structure): Empowerment, Education, and Employment which collectively enables people to achieve their capabilities, grow wealthier, and contribute to development. Such investments in human capital are necessary pre-conditions for human development and the fulfillment of basic human rights, and essential for maximizing the chances for a demographic dividend. They are not sufficient unto themselves, but must be matched by corresponding policies and investments in other sectors, including infrastructure and the business climate. 
Economic returns on the demographic transition, such as Gross Domestic Product (GDP) per capita, are usually estimated at the national level. However, demographic transitions proceed at different paces at the sub-national level within a country depending on the characteristics of subgroup populations and environmental and social conditions in the subnational area, such as population age structure, education, employment, health services, and other socio-economic factors. To date, there is no comprehensive demographic dividend index that can help identify priority areas for policy, programming, and investment in individual countries or at the sub-national level. To fill in the gap, this research proposes a method to conduct sub-national assessment of key demographic dividend related human capital indicators, identify the areas lagging behind, and enhance local development for reaping a demographic dividend.

This case study leverages the use of census data as well as the WEF/GAC framework on policies to advance prospects for a demographic dividend. The study analyzes the selected demographic dividend indicators at both the national and sub-national level, and more specifically at the district level where decision making and accountability reside. After identifying the main indicators (dependency ratio, net secondary school education attendance, child marriage, and young people not in education, employment, or training [NEET]), a geometric composite index is created that enables mapping the overall variance of human capital needs across districts and across these distinct indicators. Simulations are applied to illustrate different scenarios that can inform the development of policies and programs.

\section{Country Context}

Over the past forty years, Nepal has experienced substantial demographic changes as a result of a sharp decline in the levels of fertility and an increase in life expectancy. The total fertility rate was estimated at 2.3 children per woman for 2015, compared to five children per woman at the end of the 1990s. When factoring in the effects of migration, the population of Nepal increased from 8.5 million in 1950 to 28.5 million in 2015, and will reach 33.1 million in 2030, based on data from World Population Prospects. Life expectancy at birth increased from 56.4 years at the beginning of the 1990 s to 70.0 in 2015. The population dynamics generated by these changes in fertility, mortality, and migration are already reflected in the age structure of the population (Figure 1).

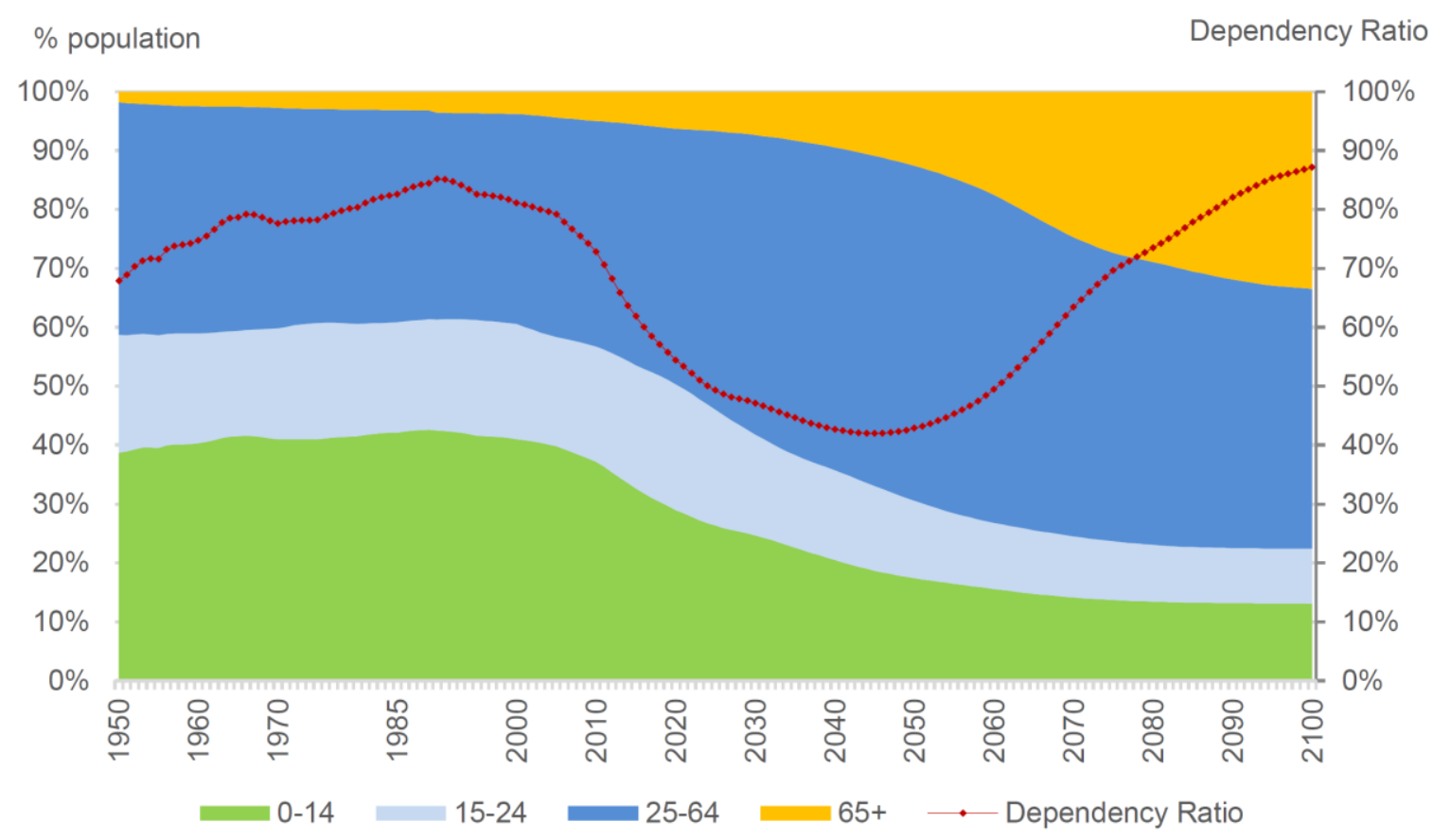

(Date source: United Nations Population Division, 2015)

Figure 1: Nepal Age Structure and Dependency Ratio 
Of particular importance for this study is the rapid increase of population aged 15-64 and its relative importance as the economically active group in Nepal when compared to the younger age population (0-14 years of age) and the elderly population (65+ years of age). The dependency ratio provides an estimate of the number of dependent persons (those under the age of 15 and those 65 and older) per 100 economically active members of the population (15-64 years of age). A relatively low dependency ratio (less than or equal to 66\%) provides countries with an opportunity for the demographic dividend. Nepal is on the cusp of an age structure that will generate the opportunity for a demographic dividend, with a dependency ratio of $62 \%$ in 2015 , a projected decline to $54 \%$ in 2020 , and projection of $47 \%$ in 2030 (Table 1(a)). Under rapid urbanization, the urban population increased from $6 \%$ in 1980 to $19 \%$ in 2015 . The urban population aged $15-64$ years increased even faster, with a decreased dependency ratio in urban areas from $73 \%$ in 1980 to $44 \%$ in 2015 (Table 1(b)). Nepal's potential for demographic dividend is time bound and requires immediate preparatory investment.

However, 2011 Nepal population census results indicate that only $45 \%$ of adolescents aged 11-15 years were attending secondary school; $15 \%$ of youth age $15-24$ years were NEET; and $32 \%$ of youth age 18-24 years were married before reaching 18 years old. Nepal is identified as one of the 40 priority countries for UNFPA programming to increase benefits for the lives of girls, women, adolescents, and youth, with the highest need and lowest ability to finance. Therefore, prioritizing where the investment should be is urgent. This research seeks to identify where priority administrative or geographic investments are most needed, and which shortfalls in empowerment, education, and employment are most serious.

Table 1: (a) Nepal's population characteristics by age, 1980-2050

\begin{tabular}{|c|c|c|c|c|c|c|}
\hline Indicators & 1980 & 2015 & 2020 & 2025 & 2030 & 2050 \\
\hline Total population & $14,890,000$ & $28,514,000$ & $30,184,000$ & $31,754,000$ & $33,104,000$ & $36,159,000$ \\
\hline Age 0-14 & $6,165,000$ & $9,314,000$ & $8,743,000$ & $8,362,000$ & $8,169,000$ & $6,301,000$ \\
\hline Age 15-64 & $8,236,000$ & $17,618,000$ & $19,547,000$ & $21,272,000$ & $22,502,000$ & $25,314,000$ \\
\hline Age 65+ & 489,000 & $1,582,000$ & $1,895,000$ & $2,120,000$ & $2,433,000$ & $4,545,000$ \\
\hline Dependency ratio & 80.8 & 61.8 & 54.4 & 49.3 & 47.1 & 42.8 \\
\hline
\end{tabular}

(b) Nepal's population characteristics by age and place of residence

\begin{tabular}{|c|c|c|c|c|c|}
\hline Indicators & $\begin{array}{l}\text { Place of } \\
\text { residence }\end{array}$ & \multicolumn{2}{|c|}{1980} & \multicolumn{2}{|c|}{2015} \\
\hline \multirow{3}{*}{$\begin{array}{l}\text { Dependency } \\
\text { ratio }\end{array}$} & Urban & \multicolumn{2}{|c|}{73.0} & \multicolumn{2}{|c|}{44.3} \\
\hline & Rural & \multicolumn{2}{|c|}{81.5} & \multicolumn{2}{|c|}{66.7} \\
\hline & & Number & $\%$ & Number & $\%$ \\
\hline \multirow{2}{*}{ Total population } & Urban & 876,000 & 6.1 & $5,295,000$ & 18.6 \\
\hline & Rural & $13,509,000$ & 93.9 & $23,147,000$ & 81.4 \\
\hline \multirow{2}{*}{ Age 0-14 } & Urban & 343,000 & 5.8 & $1,389,000$ & 14.8 \\
\hline & Rural & $5,617,000$ & 94.2 & $7,987,000$ & 85.1 \\
\hline \multirow{2}{*}{ Age 15-64 } & Urban & 507,000 & 6.4 & $3,667,000$ & 20.9 \\
\hline & Rural & $7,441,000$ & 93.6 & $13,884,000$ & 79.1 \\
\hline \multirow{2}{*}{ Age 65+ } & Urban & 27,000 & 5.7 & 236,000 & 15.7 \\
\hline & Rural & 449,000 & 94.3 & $1,272,000$ & 84.4 \\
\hline
\end{tabular}

(Data source: United Nations Population Division, 2015) 


\section{Data and Method}

Data applied in this case study are from the 2011 Integrated Public Use Microdata Series (IPUMS) census data from Nepal. Projected data are generated based on the United Nations Population Division World Population Prospects.

For the purpose of this analysis of subnational demographic dividend status, dependency ratio is analyzed as the entry point indicator to identify the opportunity for the demographic dividend. Using Bloom and Williamson's approach (1998) applied in UNFPA's report State of World Population (2014a), the three categories that indicate the presence of the opportunity for the demographic dividend according to the dependency ratio (DR) are: Low dependency ratio of less than or equal to $60 \%$ Relative low dependency ratio between less than $60 \%$ and less than or equal to $66 \%$; and Relative high dependency ratio of over $66 \%$. Dependency Ratio is calculated as: (number of children aged 0-14 + number of people aged 65 and over) ${ }^{*} 100 /$ number of people aged 15-64.

Although at the national level the opportunity for the demographic dividend is opening, at the sub-national level, the dependency ratio might have greater variation and therefore different stages regarding the demand for education, employment, and health services for the growing younger cohort, and the possibility for the demographic dividend. Once this characterization is obtained, the corresponding values for the human capital indicators at subnational level are assessed. These indicators become the main inputs for the production of the demographic dividend index (DDI).

One challenge in defining any index is the choice of indicators. In the case of human capital and the demographic dividend, there is a wide variety of potential indicators underlying aspirations of "empowerment, education, and employment". For example, IPPF (2012) advocated empowering girls including actions against child marriage as a means of achieving a demographic dividend. World Bank (2015) raised the notion that failing to address the problem of youth who are neither working nor in school could prevent a country from capturing an emerging demographic window of opportunity. Those indicators selected in this study have been chosen from those that can be estimated from the population census - allowing for widespread application of the method to multiple countries that may be limited in other sources of data. One census indicator is selected for each component of the demographic dividend " $3 \mathrm{E}$ " structure (empowerment, education, and employment). The selected variables are mutually exclusive, and widely recognized as reliable indicators of overall socio-economic development. The selected indicators and their definitions are:

- Child marriage ratio, calculated as: number of women aged 18-24 who were married before age $18^{*} 100 /$ total number of women aged 18-24.

- Secondary school Net Attendance Ratio (NAR), calculated as: number of children aged 11-15 attending secondary school * 100 / total number of children aged 11-15.

- The proportion of NEET youth 15-24 years of age, calculated as: number of NEET youth aged $15-24$ * $100 /$ total number of youth aged 15-24.

The main analysis conducted in this paper includes: 1. mapping out the spatial distribution of both the current dependency ratios and the human capital status indicators for Nepal at the district level and constructing a DDI of current human capital achievements; 2 . identifying potential policy and program development to fulfill the basic human rights and maximize the potential benefits of a demographic dividend; 3 . producing estimates (year 2020, 2025, and 2030) of the benefits of possible investments in human capital indicators under different scenarios to reach the objectives of the Sustainable Development Goals; and 4. exploring the urban rural disparities and gender inequalities using the DDI.

The DDI is produced as the geometric mean of the three defined indicators for each of the 75 districts. As a regular procedure, the distributions of these three indicators are standardized to 1-100 scale to be comparable across districts, and opposite numbers (subtracted by 100) are applied for the indicator child marriage and NEET, as these two indicators have an inversed relationship with DD Index. Districts with a DDI value below 0.5 are identified as having low human capital indicators.

Districts are ranked from highest to lowest using each district's DDI scores. The ranking of districts is then compared against the distribution of districts from the observed dependency ratio for each district to identify three priority level groups. It is anticipated that the DDI will closely represent the observed distribution of districts obtained when using the dependency ratio, and the DDI mapping will identify possible entry points for intervention at the policy and program level. 
Furthermore, the DDI is disaggregated by place of residence (urban/rural) and gender (female/male) to explore geographic disparities and gender inequalities. The results of the DDI by district are presented using maps. Projections were also generated using different future scenarios for each one of the components of the DDI for the years 2020, 2025 and 2030. The results included below offer valuable information for potential targeting of policies and interventions that would maximize benefits for girls and women and geographically disadvantaged young people.

\section{Results \\ Potentials of Harnessing Demographic Dividend at the District Level}

The district-level spatial distributions regarding the status of demographic dividend according to the DDI components and the dependency ratio in year 2011 are illustrated in Figure 2. By comparing the four maps, the districts where the human capital is low can be identified. For example, most districts located in the northeastern country have a relative low dependency ratio of lower than $66 \%$. However, most districts have a secondary school attendance rate lower than $50 \%$, with two districts lower than $40 \%$. Among the 20 districts along the south boundary of Nepal, eight districts with low dependency ratios of lower than $66 \%$ have a high NEET value of over $15 \%$. Most districts with high percentages of child marriage have a high dependency ratio. The maps suggest a need to ensure access to health services, jobs, and education, as well as an urgent effort to reduce child marriage among the districts with high proportion of vulnerable young people.

Figure 3 displays a composite DDI, which integrates the three human development components above. A full list of districts with DDI and individual indicators can be found in Annex. The mapping data demonstrate a strong correlation

between the DDI and dependency ratio. In other words, districts with a higher potential for a demographic dividend based on the dependency ratio generally show greater performance on human capital indicators.

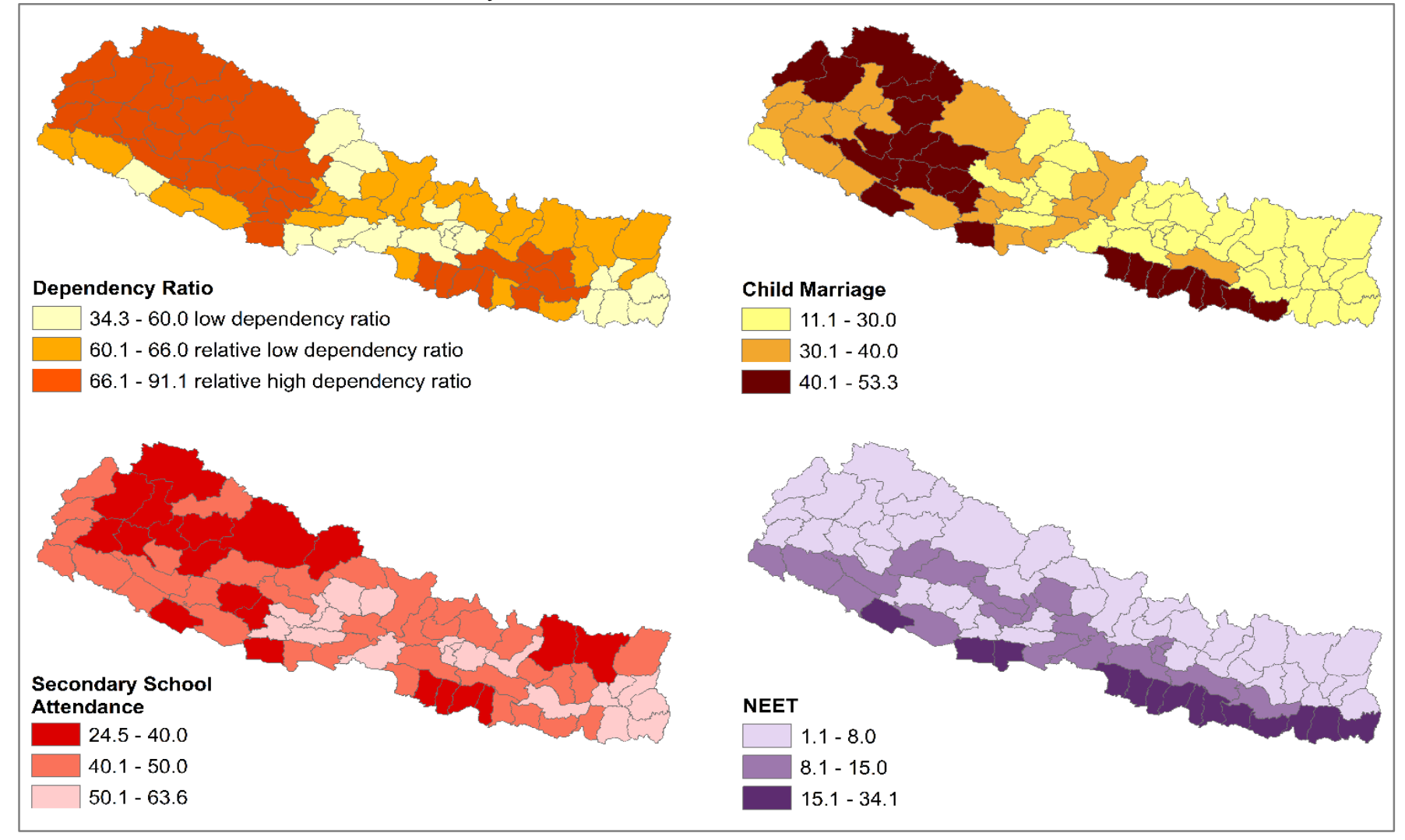

Figure 2: Geographic distribution of Dependency Ratio and DDI individual indicators 
African Population Studies Vol. 30, No. 2, (Supp.), 2016

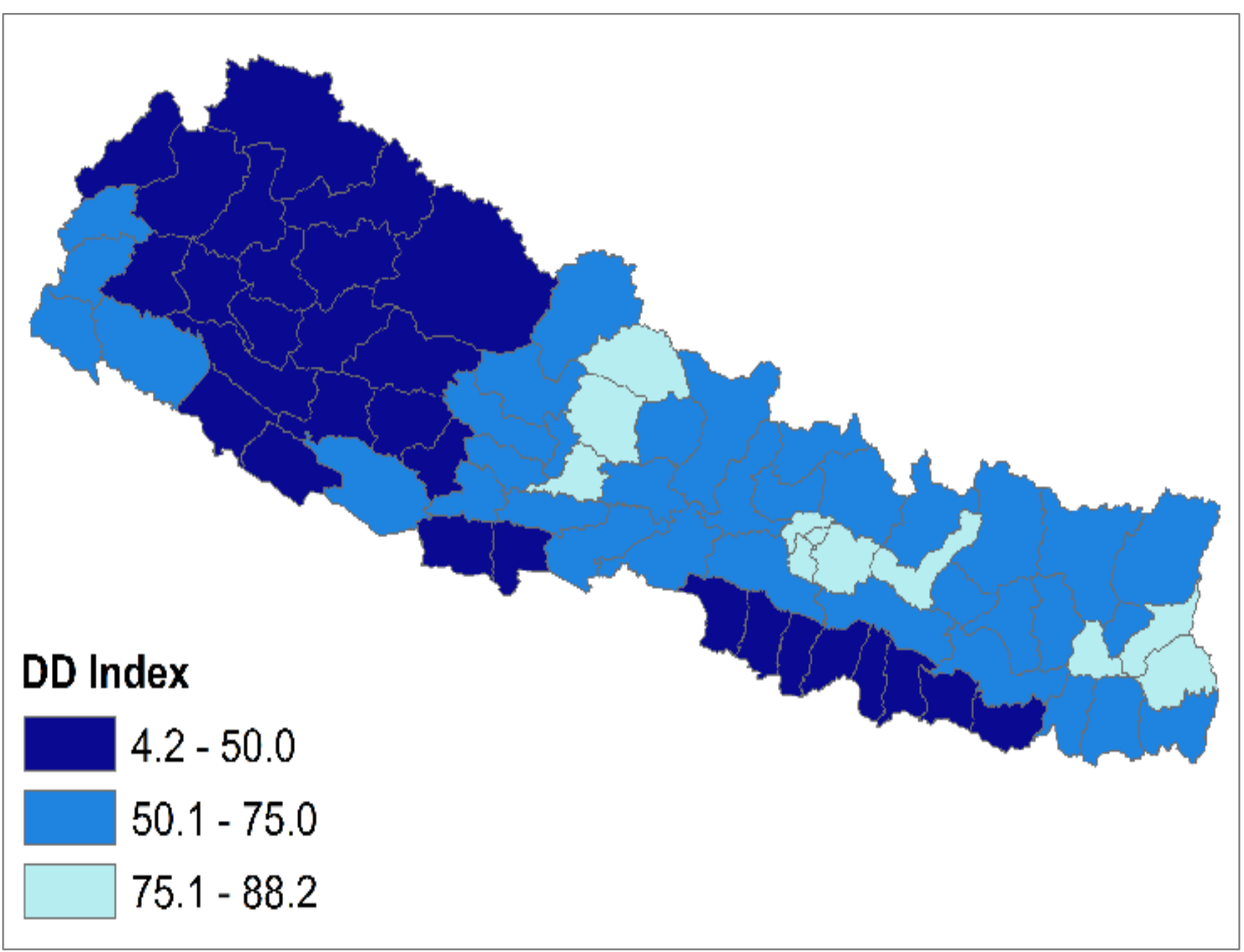

Figure 3: Geographic distributions of DDI 
Among the 75 Nepal districts, 42 districts (56\% of all districts) have entered an age profile with a dependency ratio below or equal to $66 \%$, meaning that their opportunity for achieving a demographic dividend has begun. Of these 42 districts, 19 were already below or equal to $66 \%$ as of 2015 and 23 were just entering the $66 \%$ level (Figure 4). In the remaining 33 districts, the dependency ratios are all above $66 \%$, meaning that the age structure is not favorable for a demographic dividend at present. There are 29 districts with the lowest performance on the human capital indicators (DDI <0.5), very similar to those districts in which the dependency ratio score is also on the high side. At the other end of the distribution, the DDI identified 46 districts with scores of relatively high performance on the human capital indicators (12 districts with DDI $>=0.75$ and 35 districts with DDI $>0.5$ but $<0.75)$.

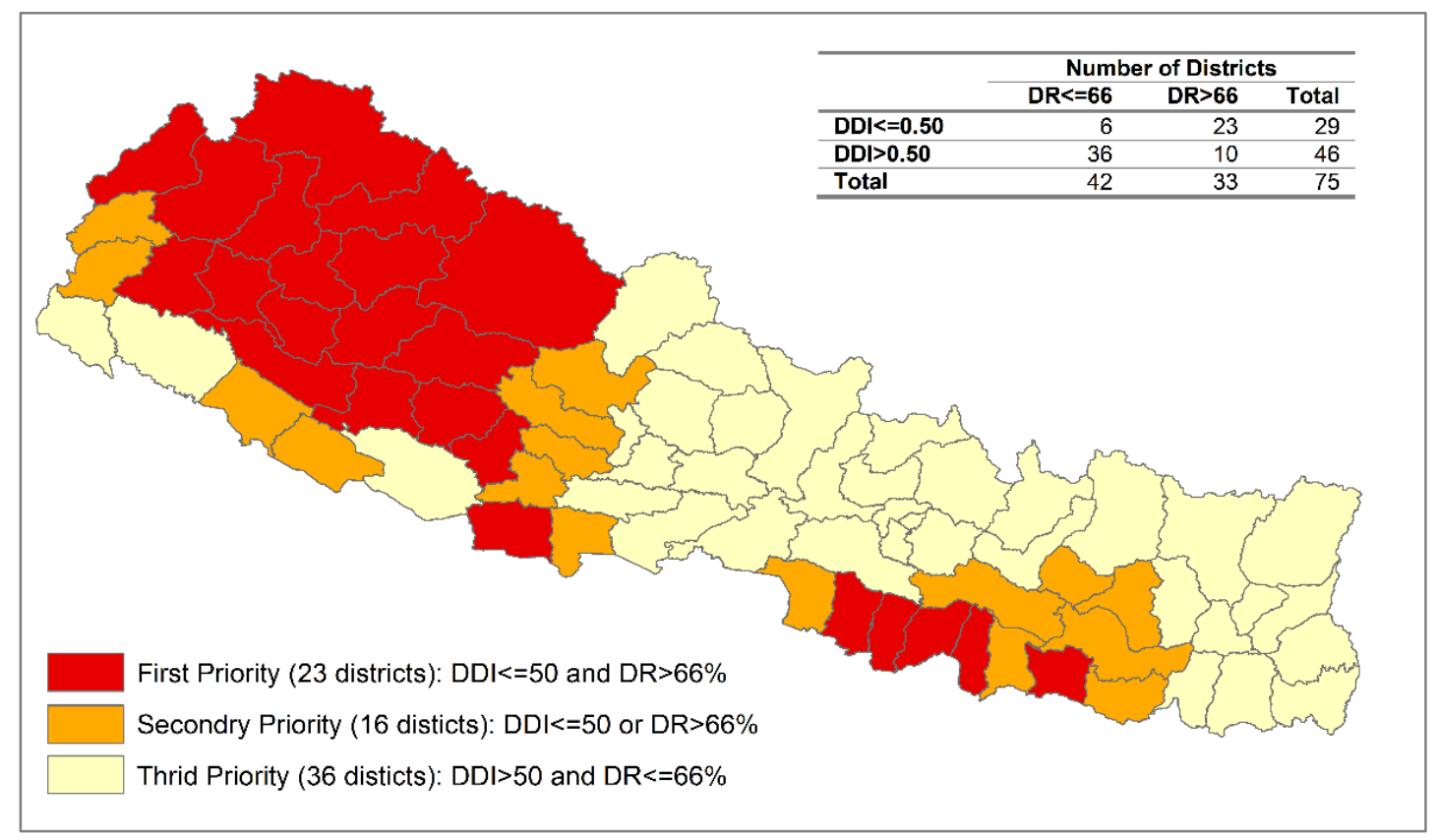

Figure 4: Priority groups of districts according to DDI and Dependency ratio

Results from the analysis reveal at least four realities from a combination of the dependency ratio and the DDI. Of the highest priority are the 23 districts in which high dependency ratios and low scores for the DDI are observed, which indicate the highest priority to eliminate harmful traditional practices and end child marriage, to provide sexual and reproductive health services, including contraception to eliminate an existing unmet need for family planning, to leave no one out of school, and ensure access to decent work.

The second group of importance for the development of policy and programs are those districts affected by either high dependency ratios or low DDI, but not both conditions (10 and 6 districts, respectively). The policies and interventions in these districts should be examined more closely, with attention to other indicators of human capital, in order that policies can be formulated to respond to the needs and conditions of each district.
Lastly, for the 36 districts that performed well in both the dependency ratio and the DDI, there may also be challenges and opportunities to maximize the benefits of favorable dependency ratios and effective investments in education, employment, and human rights. The radar chart (Figure 5) illustrates the situation of two districts, i.e. the best and the worst performing districts. Using a radar chart to present each dimension of the DDI, it is easy to identify the opening for possible interventions and set achievable targets for each of the human capital indicators. 


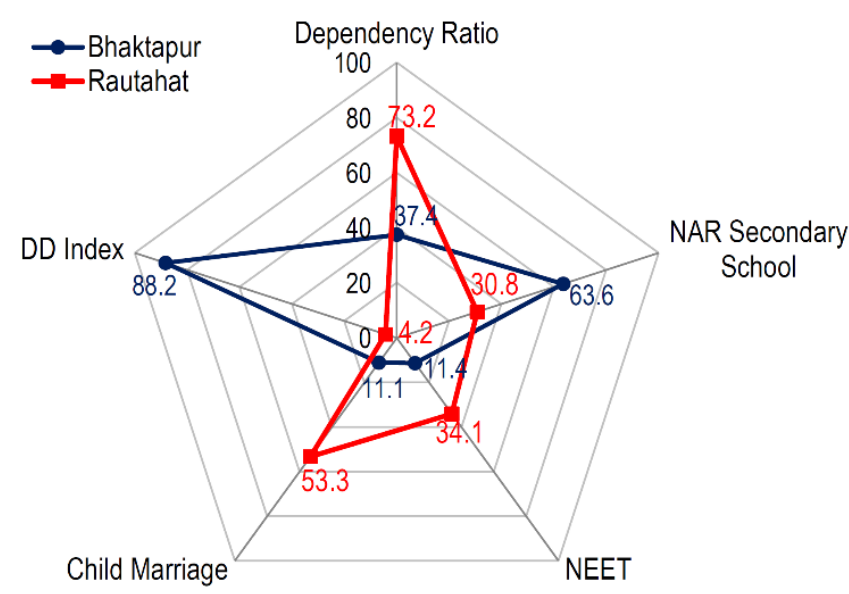

Figure 5: Comparison of demographic index and its related indicators between the top and bottom districts

\section{Challenges for the Demographic Dividend}

Given the realities presented before at the district level, it is only natural to look at the possible scenarios and challenges for the next 15 years in terms of human capital needs (empowerment, education, and employment) and the needs that would optimize the possibilities to benefit from a demographic dividend. For this purpose, three scenarios are hypothesized for each one of the key human capital indicators to identify the benefits of adopting policies and interventions during the period 2015-2030 (see Table 2).

- The Constant scenario (K) represents the result of maintaining the observed situation in 2011 during the period 20152030 (business as usual).

- In Scenario A (SA), each district will reach, by 2020 , the situation observed for the best district in 2011.

- In Scenario B (SB), it is projected that between 2015 and 2030 a $100 \%$ improvement will occur in each indicator from the values observed in 2011.

Empowerment: It is imperative to eliminate harmful traditional practices such as child marriage. With Scenario $\mathrm{K}$, the number of girls who will marry before age 18 is projected to approach 700,000 by 2020 . Although the number decreases due to the overall decline in the population of women aged $18-24$ by 2030 (from 2.1 million in 2015 to 2.2 million in 2020 to 2.0 million in 2030), the number of girls married too young will remain over 600,000 by 2030 . If the national rate of child marriage is set to that of the district with the lowest rate (Scenario SA), by year 2020, the number of child marriages would dramatically decrease to only 240,000 . However, if district officials commit to substantially reducing the incidence of child marriage among girls, in accord with Scenario B in which child marriage is reduced by half that observed in 2011 , by year 2030, the number of child marriages would decrease to less than 200,000 , and over 400,000 girls would not marry before age 18 during the period $2015-2030$.

Education: To illustrate the benefits from the policy target, the number of children aged 11-15 not attending secondary school are estimated based on the secondary school NAR. Maintaining the same situation observed in 2011 in which $45.3 \%$ of the secondary school NAR (Scenario K), the total number of children aged $11-15$ out of school will pass from 1.8 million in 2015 to 1.7 million in 2020 and to 1.5 million in 2030 , leaving a vast number of young people without education. The decline in the total number of out-of-school children during the 2015-2030 period at constant levels of school attendance is due to the past and current changes in fertility levels, with total population at age 11-15 years declining from 3.4 million in 2015 to 2.8 million in 2030. Under Scenario A (SA), in which we estimate that all districts reach $64 \%$ of secondary school participation, the highest level of participation in any given district in Nepal in 2011, over half a million children aged 11-15 years would be attending school by the end of 2020. An even more optimistic Scenario B, in which we double the level of school attendance, would benefit close to a million children aged 11-15 who would otherwise be out of school.

Employment: The total number of people aged 15-24 years will rise and then fall in the period from 2015-2030. Under constant scenario K, the number of people within this age range who are not in employment, education or training will reach 981,668 by 2020 , and then drop to 862,431 by 2030 . Corresponding to Scenario $A$ (SA), assuming that all districts reduce the NEET values to $11.4 \%$, the lowest value for a district in 2011, nearly 250,000 additional young people will be employed, in education, or in training. Corresponding to Scenario $\mathrm{B}$, if the NEET values are reduced by half to $7.5 \%$ in 2030 , close to half a million additional young people will be employed, in education, or in training.

To reach these goals, government officials will need to have strong commitments to the 
in particular; optimize education; and provide decent jobs and income opportunities.

Table 2: Three Scenarios: projections of benefits from setting targets for each human capital indicators, 2015-2030

Empowerment: Number of women aged 18-24 married/in union before age 18

\begin{tabular}{|c|c|c|c|}
\hline & Year 2015 & Year 2020 & Year 2030 \\
\hline K (target: $31.7 \%$ ) & 651,464 & 689,359 & 612,278 \\
\hline SA (target: 11.1\%) & -- & 242,503 & -- \\
\hline SB (target: 15.9\%) & -- & -- & 193,242 \\
\hline Benefits from target & -- & 446,856 & 419,036 \\
\hline \multicolumn{4}{|c|}{$\begin{array}{l}\text { Education: Number of people aged 11-15 not attending secondary school based on the secondary school } \\
\text { participation (\%) }\end{array}$} \\
\hline & Year 2015 & Year 2020 & Year 2030 \\
\hline K (target: 45.3\%) & $1,846,764$ & $1,740,043$ & $1,522,525$ \\
\hline SA (target: 63.6\%) & -- & $1,158,649$ & -- \\
\hline SB (target: $80.0 \%$ ) & -- & -- & 557,038 \\
\hline Benefits from target & -- & 581,394 & 965,487 \\
\hline \multicolumn{4}{|c|}{ Employment: Number of people aged 15-24 not in employment, education or training (\%) } \\
\hline & Year 2015 & Year 2020 & Year 2030 \\
\hline K (target: 15.2\%) & 906,830 & 980,668 & 862,431 \\
\hline SA (target: $11.4 \%$ ) & -- & 735,332 & -- \\
\hline SB (target: 7.5\%) & -- & -- & 425,494 \\
\hline Benefits from target & -- & 245,336 & 436,937 \\
\hline
\end{tabular}

\section{Urban and Rural Disparities}

One challenge of sustainable development is the uneven development between urban and rural areas. In Nepal, there are 58 municipalities identified by the national statistical office as "urban". The total urban population counts for around $20 \%$ of the study population aged 15-24, and $14 \%$ of the population at school age of 11 15 (Table 3). These 58 municipalities are located in 43 districts, mostly in the southwestern lowlands, or terai area. Figure 6 shows the distribution of districts that are urban. The remaining 32 districts are without urban municipality, and therefore, are identified as

\section{Table 3: Urban and rural population for the population at the study age}

\begin{tabular}{lrrr}
\hline & \multicolumn{3}{c}{ Population } \\
\cline { 2 - 4 } & Age & Age & Age \\
& $\mathbf{1 1 - 1 5}$ & $\mathbf{1 5 - 2 4}$ & $\mathbf{1 8 - 2 4}$ \\
\hline \multirow{2}{*}{ Total } & 428140 & 673484 & 437384 \\
\hline \multirow{2}{*}{ Rural } & 367145 & 549207 & 350304 \\
& $(86 \%)$ & $(82 \%)$ & $(80 \%)$ \\
\hline \multirow{2}{*}{ Urban } & 60995 & 124277 & 87080 \\
& $(14 \%)$ & $(18 \%)$ & $(20 \%)$ \\
\hline
\end{tabular}

districts with $100 \%$ rural population.

Following the sub-national district level analysis of the DDI, the analysis is further broken down by urban and rural, male and female population. Table 4 illustrates an overall comparison of the three demographic dividend indicators by place of residence and gender. The rural population has a much higher dependency ratio than the urban population, particularly among the male population group. The rural male population has a high dependency ratio of $80.2 \%$, while the urban male population has a low dependency ratio of $51.4 \%$. Secondary school attendance showed a contrast between urban (58\%) and rural (43.2\%). Not much difference is found on NEET between urban and rural population. However, gender inequality is consistent in both urban and rural areas, with higher percentages of child marriage for women in both areas. Child Marriage in rural areas is nearly two times that in urban areas $(24.1 \%$ and $10.9 \%$ respectively). To illustrate how the indicators, distribute among districts, each indicator is presented using individual maps. 


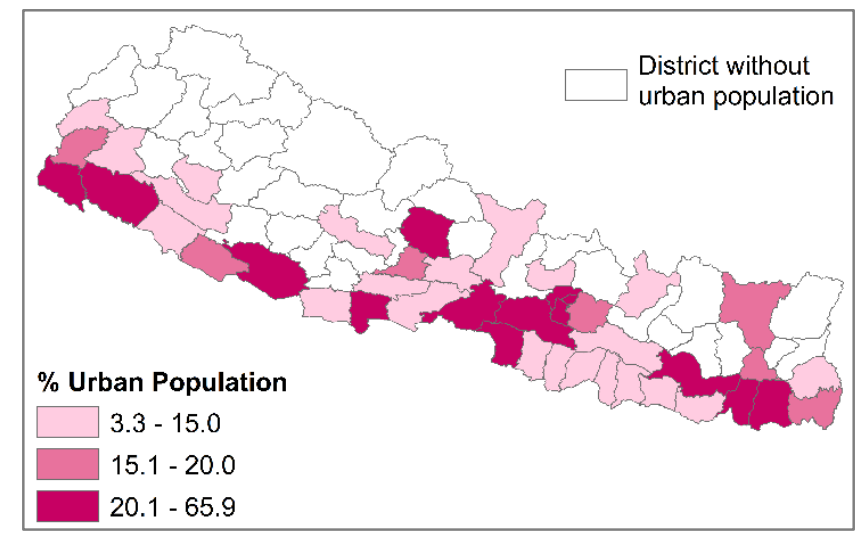

Figure 6: Proportion of urban populations

Table 4: DDI indicators and Dependency Ratio disaggretation by gender and location

\begin{tabular}{|c|c|c|c|c|c|}
\hline & & \multirow[b]{2}{*}{ Dependency Ratio } & \multirow{2}{*}{$\begin{array}{c}\text { Empowerment } \\
\% \text { Child Marriage }\end{array}$} & \multirow{2}{*}{$\begin{array}{l}\text { Education } \\
\text { Secondary } \\
\text { School NAR }\end{array}$} & \multirow{2}{*}{$\begin{array}{c}\text { Employment } \\
\text { NEET }\end{array}$} \\
\hline & & & & & \\
\hline Total & & 68.4 & 21.4 & 45.3 & 15.2 \\
\hline Female & & 63.0 & 31.7 & 44.8 & 22.9 \\
\hline Male & & 74.6 & 8.8 & 45.9 & 6.3 \\
\hline \multirow[t]{3}{*}{ Rural } & & 72.7 & 24.1 & 43.2 & 15.2 \\
\hline & Female & 66.3 & 34.7 & 42.5 & 22.4 \\
\hline & Male & 80.2 & 10.4 & 44.0 & 6.5 \\
\hline \multirow[t]{3}{*}{ Urban } & & 49.0 & 10.9 & 58.0 & 15.4 \\
\hline & Female & 46.7 & 18.3 & 59.1 & 25.1 \\
\hline & Male & 51.4 & 3.3 & 56.9 & 5.6 \\
\hline
\end{tabular}

Figure $7(a)$ shows the dependency ratio and three DDI indicators for all urban populations in the 43 districts. All districts except one have a low dependency ratio of $<=66 \%$. Thirty-two districts have a secondary school attendance rate of $50 \%$ or above, and only three districts have a rate of less than $40 \%$. Through spatial distribution of the school attendance rate, low secondary school attendance rate values are mainly distributed in the south and east of the county. The districts with high NEET values are clustered in the south. Figure 7(b) shows the results of DDI indicators for all rural populations in the 75 districts. Because more than $80 \%$ of the population aged 11-24 are part of the rural population, the spatial distribution of the DDI indicators presents a very similar pattern of that for the total population (Figure 2). Compared to urban DDI distribution, the secondary school attendance rate is much lower across the country (19 districts have a secondary school attendance rate of $50 \%$ or above, and 23 districts have a rate of less than $40 \%$ ). Child marriage presents two clusters for rural girls: in the far western mountain region and in the southeast of the country. Compared to urban girls, rural girls have a much higher proportion and a wider range of spatial distribution of child marriage. Higher NEET populations are more clustered in the southeast country. 


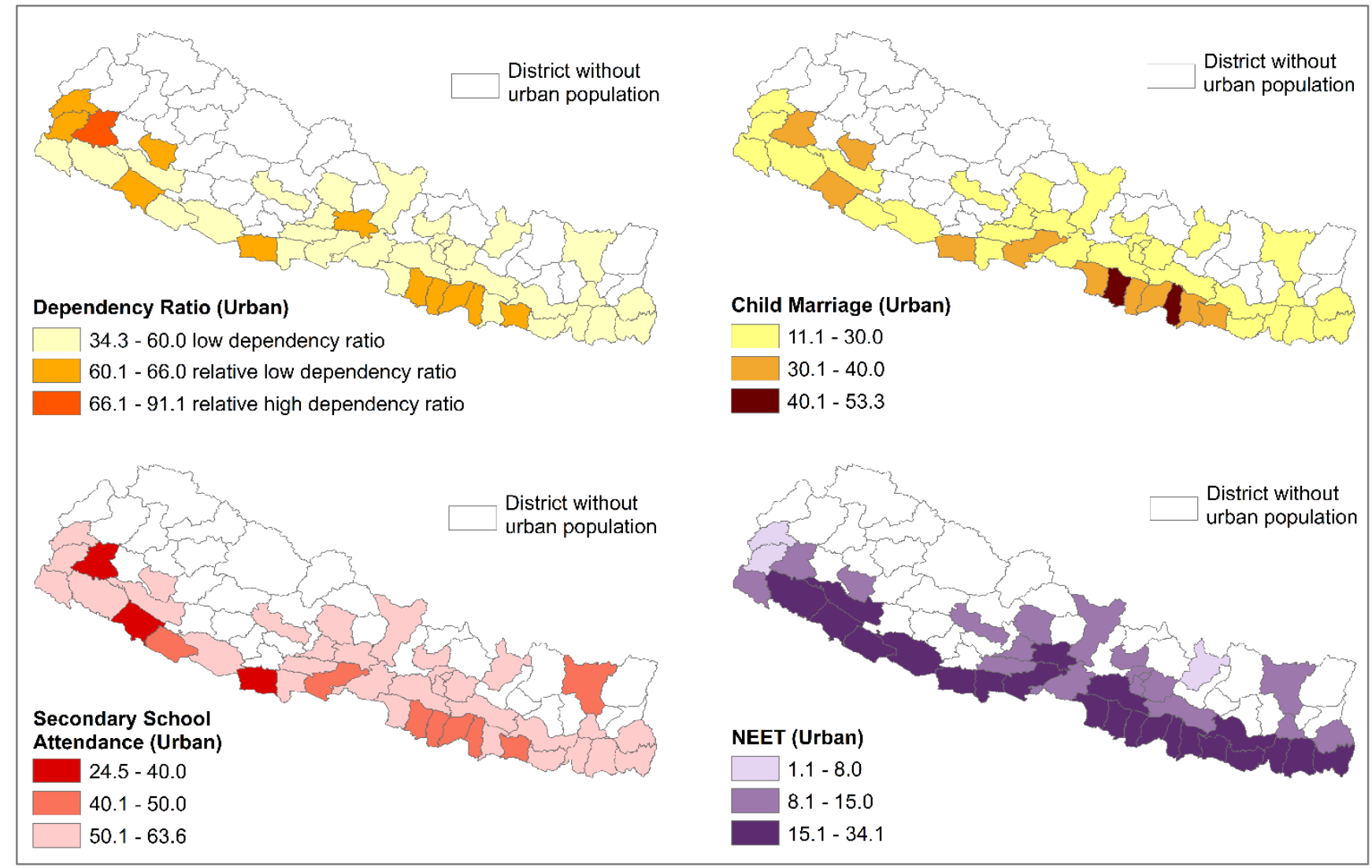

(a) Urban population

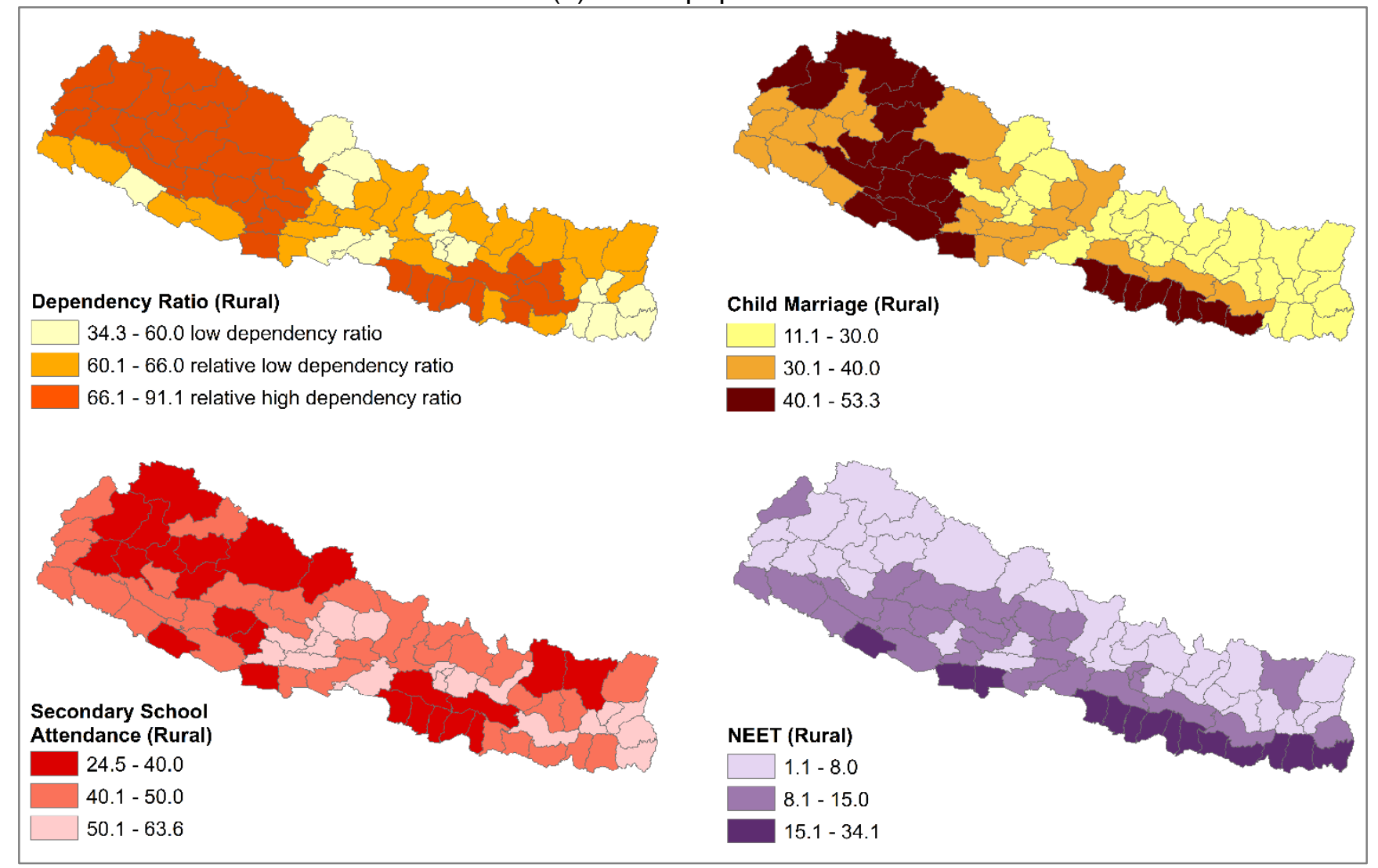

(b) Rural population

Figure 7: Geographic distributions of Dependency Ratio and DD Index, by urban by rural

Table 5 shows the priority districts using the method proposed. For urban population (Table $5(a))$, the highest priority is the only one district with a high dependency ratio and a low score for DDI (less than 0.50). The secondary priority group contains the 11 districts with a low 
dependency ratio of $<=66 \%$, suggesting a potential for demographic dividend, and a DDI score of lower than 0.50 . For rural population (Table 5(b)), there are 23 top priority districts with a high dependency ratio and low DDI. Seventeen secondary priority districts are identified, including six districts with a low dependency ratio and low DDI scores, and 11 districts with a high dependency ratio. For these districts with a high dependency ratio, young people aged $0-14$ count nearly 6 times that of old people aged 65+, and enhancing school attendance and education levels are urgently needed.

Table 5: Distribution of districts according to DDI and Dependency ratio, by urban and rural

(a) Urban population

(b) Rural population

\begin{tabular}{|c|c|c|c|c|c|c|c|}
\hline & \multicolumn{3}{|c|}{$\begin{array}{c}\text { Number of Districts } \\
\text { (with urban population) }\end{array}$} & & \multicolumn{3}{|c|}{$\begin{array}{l}\text { Number of Districts } \\
\text { (with rural population) }\end{array}$} \\
\hline & $\mathrm{DR}<=66$ & $\mathrm{DR}>66$ & Total & & $D R<=66$ & $\mathrm{DR}>66$ & Total \\
\hline $\mathrm{DDI}<=0.50$ & 11 & 1 & 12 & $\mathrm{DDI}<=0.50$ & 6 & 23 & 29 \\
\hline DDI $>0.50$ & 31 & 0 & 31 & DDI>0.50 & 35 & 11 & 46 \\
\hline Total & 42 & 1 & 43 & Total & 41 & 34 & 75 \\
\hline
\end{tabular}

Figure 8 illustrates the distribution of each indicator for both urban and rural populations among the 43 districts. The urban population has an overall high school attendance rate and lower child marriage level. Although the NEET values among total urban and total rural populations are nearly the same, in both urban and rural areas, important disparities are observed between men and women who are NEET (Table 4). The spatial distribution among districts are different, and the median of urban people having NEET is slightly higher than that of the rural population (Figure 8). The distribution of NEET values are observed consistent with topographic characteristics lower numbers in the mountain, and higher numbers in the terai (Figure 7).

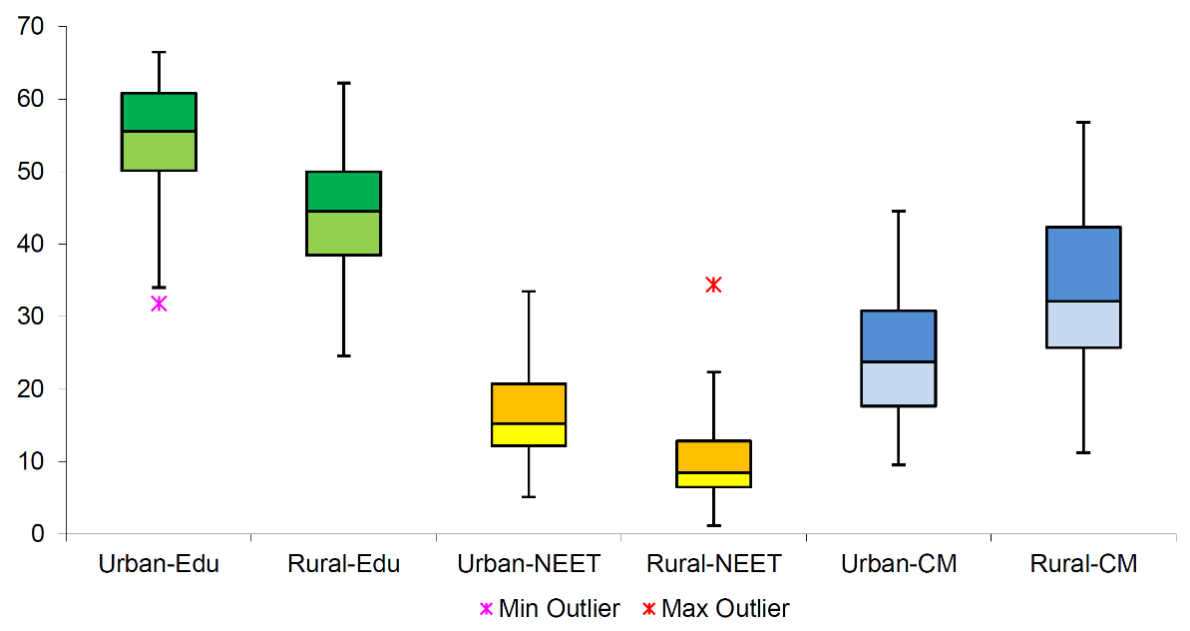

Figure 8: Distribution of DDI indicators by urban and rural population

The aforementioned disparity between men and women can be explained with the numbers included in Figure 9. For males, the low NEET values are associated with higher involvement in employment and in education than females. Furthermore, Figure 9 indicates that, among the NEET populations, while female NEET spend most of their time in household work, their male counterparts have a more even distribution of spending their time. In average, for both urban and rural population, men who are NEET spend nearly four months seeking a job, three months doing household work, and five months neither doing housework nor seeking a job. In contrast, women who are NEET spend their majority of their time, 11 months, on household work.

For both urban and rural populations, the results reveal that: Firstly, areas with similar characteristics (e.g., child marriage) present strong spatial relationships - they are clustered rather than dispersed. Secondly, the three dimensions, in the demographic dividend have 
relationship with each other: for districts where the education level is lower, the child marriage is correspondently higher, with an $\mathrm{R}$ square of 0.4 . This suggests that the three dimensions could have influence on each other, formulating a positive circulation towards a demographic dividend. Thirdly, the comparison between Figure 7(a) and 6(b) makes it possible to identify the districts where urban and rural population present similar or different levels for the three indicators. For example, the two maps show that districts with a lower school attendance rate in the urban population also have a lower school attendance in the rural population compared to other districts, although the overall attendance rate in the rural population is lower than the urban population. At the same time, the maps could also target the districts with important disparities among their urban and rural populations regarding the three indicators.

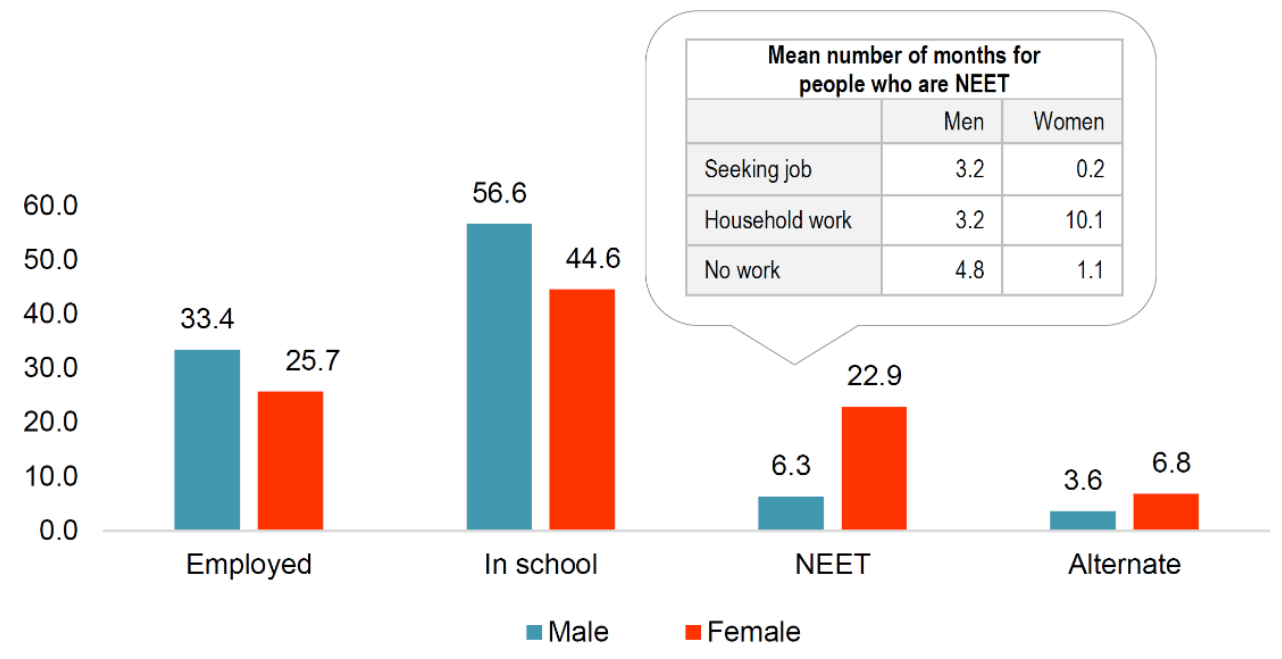

Figure 9: Employment status among people aged 15-24

DDI analysis based on urban and rural population disaggregation reveals the inequality within each district. The two radar charts (Figure 10) with examples of two districts illustrate that Bhaktapur, the best performing district with the highest DDI value, has very similar values for the three indicators between urban and rural population. However, Parsa, the worst performing district based on rural population, has a stark difference in empowerment, education, and employment levels between its urban and rural populations. The analysis for each indicator at district level and the disaggregation by urban and rural will be a useful reference for programming and taking action to meet the targets for each indicator and reducing the inequalities among districts, as well as the urban and rural inequalities within each district.

The male/female analysis among youth aged 1524 revealed first, greater participation of males in education and employment and much lower NEET percentages than their female counterparts. Second, the NEET analysis indicated that females had spent the majority of their time (11 months) in household work while men distributed their time more evenly between household work, seeking employment, or just idling. These set of findings present important challenges for policy and decision makers of future investments, in particular to grant greater opportunities for women in education and employment. 


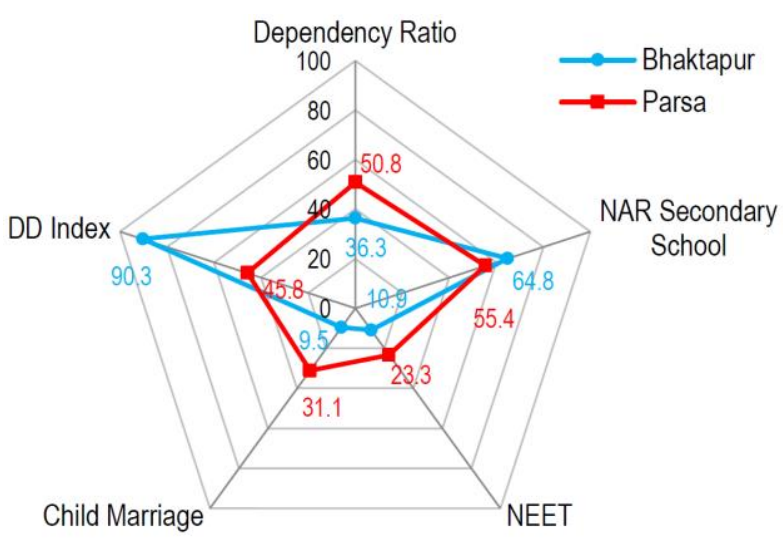

(a) Urban population

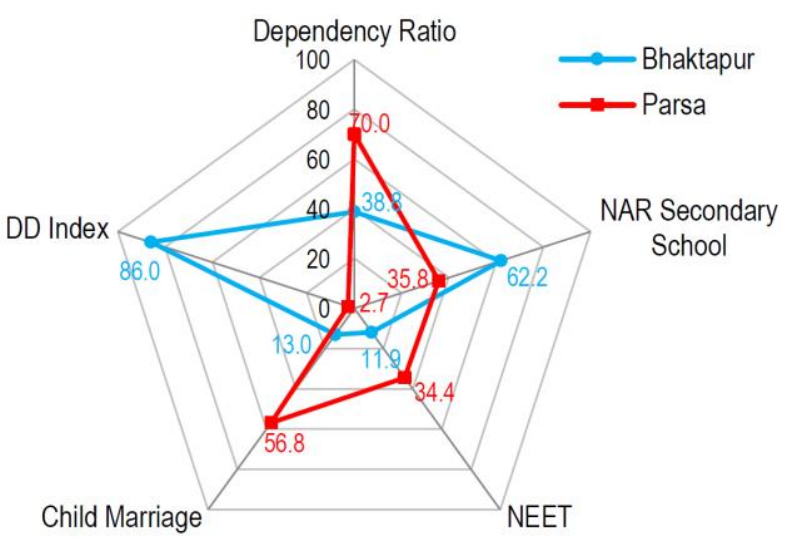

(b) Rural population

Figure 10: Comparison of demographic index and its related indicators between the top and bottom districts, by urban and rural

\section{Discussion}

The demographic dividend index has the potential for replication in other countries (and/or including other specific and contextual indicators). For example, when applying the methodology to African countries, the indicator for empowerment could be women's unmet need for family planning, girls and women who have undergone female genital mutilation, etc. The age selection for each indicator is also different from country to country. For example, the secondary school age population in Zambia is the population aged $14-18$ years (CSO [Zambia] et al., 2014), whereas the secondary school age is 11-15 in Nepal (MOHP [Nepal] et al., 2012). Data availability for high geospatial disaggregation could be critical for accountability, particularly with regard to health related indicators. There is a need for innovative methodology for a sub-national DDI analysis such as the application of small area estimation - a method that makes it possible to bridging census and household survey data to estimate indicators at a small area level (Rao and Molina, 2015). In addition, migration issues and the dynamics of population could be a challenge when conducting analysis at sub-national level. Therefore, the involvement of national and local government in the indicator selection and data provisioning will be helpful to ensure the high quality of analysis and the right policy actions and programming. Because the method suggests selecting one key indicator as a representation of each dimension in the $3 \mathrm{E}$ framework, the limitation of the proposed method could be that key issues in the dimension are not covered. In this light, two or three customized indicators per category could be considered based on the county context. The proposed method has a certain level of flexibility for customization when it is applied to various countries.

Although the DDI provides a methodology that facilitates policy makers with the ability to identify the districts that lag behind but have the potential for development, reaping a demographic dividend needs a long-term strategy. Each element does not stand alone but interacts and associates with other factors. For example, in our case studies of African countries, girls living in poor households, not attending school, or living in rural areas are more likely to be married before the age of 18 ; child marriage rate is positively correlated to adolescence pregnancy rate. The goal of ending child marriage needs to be dealt with in a holistic manner. In-depth understanding within each district with further data disaggregated can help in enhancing local development. The data disaggregation by gender and place of residence (urban or rural) in this research illustrates a status of gender and place inequalities regarding child marriage, education, and employment among all the districts. For future work, it will be worthwhile to explore the reasons and drivers behind data; for example, there is not much difference between urban and rural population who are NEET, and further study could explore the reasons that urban young people have a higher school attendance ratio compared to rural people while the NEET remains higher, particularly among urban women.

\section{Conclusion}

This research adopted the "3E" policy framework with the three dimensions of empowerment, education and employment, and measured selected demographic dividend-related 
indicators at the sub-national level in Nepal, identifying high priority areas for human capital development. The DDI integrates the most typical indicators in each category of the framework and provides a reference for policy makers to target priority areas where the three categories of human capital are urgently needed. By combining with dependency ratio, this research proposed a method to identify the top priority areas and secondary priority areas. Radar charts are used to illustrate the overall DDI score and each indicator value, while the individual indicator map shows "where" these priority areas are located.

Using Nepal as a case study, this research applied the methodology for demographic dividend analysis. Results show that the districts are at different stages of demographic transition, with different stages of demographic opportunities and challenges. By combining dependency ratio and DDI, the 74 districts are classified in three priority groups. Urban population presents a much lower dependency ratio and a higher DDI, particularly a higher school attendance and lower child marriage. For each individual indicator, urban and rural disparities are found at district level. Important gender inequalities were observed and analyzed, particularly in the much higher proportion of women who are NEET and who spent more of their time in household work.

The proposed DDI and analysis method can be applied to assess demographic dividendrelated human capitals at the sub-national level and explore geographical disparities and urban/rural inequalities. When projected to 2020 and 2030 with absolute values, the DDI indicators can be used for scenario analysis, and the benefit of setting different targets can be measured. The results of this case study provide policy makers an overview of the spatial distribution of human capital variance within Nepal, identifying districts where human capital investment is most needed to capitalize on changes in age structure favorable to a demographic dividend.

\section{Acknowledgment}

We would like to thank the United Nations Population Fund (UNFPA) Nepal Country Office and the Nepal Central Bureau of Statistics for their support to this research and for providing us access to the census data. Thanks to Dr. Pablo Salazar Canelos, Dr. Jean Francois Kobiane and anonymous reviewers for their valuable comments, and thanks to UNFPA Zambia for adopting the methods developed through this case study for an integrated analysis of sub-national programming and challenges for achieving a demographic dividend in Zambia.

\section{References}

Bloom, D. E., and Williamson, J.G. 1998. Demographic Transitions and Economic Miracles in Emerging Asia. World Bank Economic Review, 12(3):419-455.

Central Statistical Office (CSO) [Zambia], Ministry of Health (MOH) [Zambia], and ICF International. 2014. Zambia Demographic and Health Survey 2013-14. Rockville, Maryland, USA: Central Statistical Office, Ministry of Health, and ICF International.

French Agency for Development (FAD) and World Bank (WB). 2015. Africa's Demographic Transition: Dividend or Disaster? Washington, DC: World Bank.

International Planned Parenthood Federation (IPPF). 2012. The girl dividend: why girls matter for economic growth and development. London: IPPF.

Ministry of Health and Population (MOHP) [Nepal], New ERA, and ICF International Inc. 2012. Nepal Demographic and Health Survey 2011. Kathmandu, Nepal: Ministry of Health and Population, New ERA, and ICF International, Calverton, Maryland.

Rao, J.N.K. and Molina, I. 2015: Small Area Estimation, Second Edition. John Wiley \& Sons, Inc., Hoboken. (ISBN: 978-1-11873578-7).

United Nations Population Fund. 2014a. State of World Population report "The Power of 1.8 Billion: Adolescents, Youth and the Transformation of the Future". New York: UNFPA.

- 2014b. Harnessing the Demographic Dividend: Accelerating socioeconomic transformation in Uganda. Uganda: UNFPA.

- 2015a. Taking Advantage of the Demographic Dividend in Indonesia: A Brief Introduction to Theory and Practice. Indonesia: UNFPA.

- 2015b. Synthesis Report on the Demographic Dividend in Africa. Johannesburg: UNFPA-Regional office.

United Nations, Department of Economic and Social Affairs, Population Division (UNPD). 2015. 2015 Revision of World Population Prospects. New York: United Nations Population Division.

World Bank Group. 2015. Out of School and Out of Work: Risk and Opportunities for Latin America's Ninis. Washington, DC: World Bank. 
World Economic Forum (WEF). 2015. A Report by the Global Agenda Council on the Demographic Dividend: "A 3E Policy Framework to Reap the Demographic Dividend: Empower, Educate, Employ" at the
2015 World Economic Forum. Available from: http://www.weforum.org/content/globalagenda-council-demographic-dividend-20142016-0.

ANNEX. Distribution of districts according to dependency ratio, human capital indicators (Secondary School NAR, NEET and Child Marriage) and DDI using Nepal 2011 population census)

\begin{tabular}{|c|c|c|c|c|c|c|c|}
\hline District & Sub-region & DDI Rank & DD Index & $\begin{array}{r}\text { Dependency } \\
\text { Ratio }\end{array}$ & $\begin{array}{r}\text { Secondary } \\
\text { School } \\
\text { NAR }\end{array}$ & NEET & $\%$ Child Marriage \\
\hline Bhaktapur & Central hill & 1 & 88.2 & 37.4 & 63.6 & 11.4 & 11.1 \\
\hline Kathmandu & Central hill & 2 & 85.1 & 34.3 & 62.1 & 12.4 & 12.0 \\
\hline Lalitpur & Central hill & 3 & 84.8 & 36.6 & 61.3 & 11.2 & 13.6 \\
\hline Ilam & Eastern hill & 4 & 79.3 & 48.6 & 57.0 & 8.4 & 20.8 \\
\hline Syangja & Western hill & 5 & 79.2 & 62.4 & 62.6 & 8.2 & 25.9 \\
\hline Kavrepalanchok & Central hill & 6 & 77.7 & 50.2 & 52.4 & 8.8 & 17.2 \\
\hline Kaski & Western hill & 7 & 77.2 & 47.9 & 61.4 & 13.7 & 20.2 \\
\hline Panchthar & Eastern hill & 8 & 76.9 & 60.7 & 52.2 & 7.4 & 19.8 \\
\hline Ramechhap & Central hill & 9 & 76.4 & 64.3 & 51.4 & 5.8 & 21.5 \\
\hline Dhankuta & Eastern hill & 10 & 76.0 & 56.2 & 52.7 & 7.1 & 21.8 \\
\hline Manang & Western mountain & 11 & 76.0 & 39.3 & 44.9 & 6.3 & 11.2 \\
\hline Terhathum & Eastern hill & 12 & 74.8 & 59.3 & 55.0 & 7.2 & 25.6 \\
\hline Chitawan & Central terai & 13 & 71.7 & 49.5 & 56.3 & 13.1 & 23.5 \\
\hline Palpa & Western hill & 14 & 71.2 & 62.7 & 52.6 & 6.5 & 28.1 \\
\hline Dolakha & Central mountain & 15 & 70.8 & 63.8 & 44.1 & 4.8 & 19.8 \\
\hline Parbat & Western hill & 16 & 70.3 & 63.2 & 56.5 & 9.9 & 29.0 \\
\hline Bhojpur & Eastern hill & 17 & 69.7 & 63.0 & 45.8 & 5.7 & 22.9 \\
\hline Jhapa & Eastern terai & 18 & 68.9 & 49.8 & 56.3 & 18.0 & 19.0 \\
\hline Khotang & Eastern hill & 19 & 68.7 & 71.0 & 48.7 & 7.1 & 26.5 \\
\hline Okhaldhunga & Eastern hill & 20 & 67.9 & 69.1 & 47.4 & 7.2 & 25.8 \\
\hline Taplejung & Eastern mountain & 21 & 67.5 & 66.0 & 45.7 & 7.0 & 24.4 \\
\hline Nuwakot & Western mountain & 22 & 67.1 & 57.8 & 46.7 & 8.3 & 24.9 \\
\hline Mustang & Western mountain & 23 & 67.1 & 37.2 & 39.3 & 6.1 & 14.1 \\
\hline Solukhumbu & Eastern mountain & 24 & 66.4 & 62.2 & 38.7 & 4.1 & 16.3 \\
\hline Udayapur & Eastern hill & 25 & 65.8 & 67.1 & 52.2 & 11.2 & 29.1 \\
\hline Sindhupalchok & Central mountain & 26 & 65.6 & 60.3 & 44.5 & 7.8 & 24.4 \\
\hline Lamjung & Western hill & 27 & 65.4 & 60.9 & 51.7 & 8.7 & 31.5 \\
\hline Arghakhanchi & Western hill & 28 & 64.6 & 72.8 & 53.0 & 8.3 & 33.7 \\
\hline Gulmi & Western hill & 29 & 63.3 & 70.2 & 51.3 & 9.7 & 32.5 \\
\hline Gorkha & Western hill & 30 & 62.8 & 64.6 & 46.0 & 7.5 & 30.0 \\
\hline Baglung & Western hill & 31 & 62.2 & 66.7 & 46.5 & 11.1 & 27.9 \\
\hline Kanchanpur & Far-western terai & 32 & 60.6 & 63.2 & 47.5 & 12.4 & 29.5 \\
\hline Myagdi & Western hill & 33 & 60.3 & 66.5 & 45.9 & 8.6 & 31.8 \\
\hline Rasuwa & Central mountain & 34 & 60.1 & 62.5 & 41.6 & 6.6 & 28.7 \\
\hline Dhading & Central hill & 35 & 60.1 & 64.2 & 42.3 & 7.9 & 28.3 \\
\hline Tanahu & Western hill & 36 & 58.7 & 62.2 & 49.6 & 12.7 & 33.3 \\
\hline Morang & Eastern terai & 37 & 57.8 & 51.7 & 50.8 & 20.4 & 25.2 \\
\hline Sankhuwasabha & Eastern mountain & 38 & 57.8 & 64.4 & 39.0 & 8.7 & 25.4 \\
\hline
\end{tabular}


African Population Studies Vol 30, No 2, (Supp.), 2016

\begin{tabular}{|c|c|c|c|c|c|c|c|}
\hline Dadeldhura & Far-western hill & 39 & 56.8 & 75.8 & 43.2 & 5.5 & 35.1 \\
\hline Makwanpur & Central hill & 40 & 56.4 & 59.5 & 40.3 & 11.5 & 26.6 \\
\hline Nawalparasi & Western terai & 41 & 55.5 & 57.0 & 45.0 & 14.7 & 30.6 \\
\hline Sindhuli & Central hill & 42 & 55.2 & 71.1 & 41.5 & 10.4 & 31.2 \\
\hline Sunsari & Eastern terai & 43 & 53.7 & 53.7 & 47.5 & 21.5 & 25.4 \\
\hline Baitadi & Far-western hill & 44 & 53.0 & 77.5 & 41.4 & 5.7 & 37.0 \\
\hline Kailali & Far-western terai & 45 & 52.9 & 60.6 & 43.0 & 14.2 & 32.1 \\
\hline Dang & Mid-western terai & 46 & 51.4 & 60.1 & 47.8 & 14.7 & 37.6 \\
\hline Bardiya & Mid-western terai & 47 & 49.8 & 57.2 & 43.3 & 13.1 & 37.0 \\
\hline Mugu & Western mountain & 48 & 47.8 & 77.1 & 40.6 & 2.2 & 42.3 \\
\hline Dailekh & Mid-western hill & 49 & 47.5 & 77.6 & 43.1 & 7.6 & 42.0 \\
\hline Rupandehi & Western terai & 50 & 46.3 & 57.3 & 44.1 & 21.3 & 32.8 \\
\hline Darchula & Western mountain & 51 & 45.5 & 72.6 & 47.7 & 8.6 & 45.2 \\
\hline Surkhet & Mid-western hill & 52 & 45.2 & 67.2 & 47.3 & 13.3 & 43.3 \\
\hline Kalikot & Western mountain & 53 & 45.0 & 83.1 & 33.3 & 5.7 & 34.4 \\
\hline Achham & Far-western hill & 54 & 45.0 & 91.1 & 33.0 & 6.8 & 32.9 \\
\hline Salyan & Mid-western hill & 55 & 44.7 & 70.2 & 42.6 & 8.4 & 43.5 \\
\hline Rukum & Mid-western hill & 56 & 43.7 & 72.0 & 42.5 & 10.7 & 43.1 \\
\hline Pyuthan & Mid-western hill & 57 & 42.3 & 84.0 & 35.7 & 6.0 & 41.0 \\
\hline Bajura & Western mountain & 58 & 39.8 & 85.5 & 32.2 & 4.2 & 39.5 \\
\hline Saptari & Eastern terai & 59 & 39.7 & 63.0 & 47.1 & 22.5 & 41.3 \\
\hline Dolpa & Western mountain & 60 & 39.4 & 68.7 & 30.6 & 3.0 & 37.0 \\
\hline Banke & Mid-western terai & 61 & 33.6 & 60.8 & 39.8 & 23.8 & 41.4 \\
\hline Bajhang & Western mountain & 62 & 31.4 & 87.0 & 31.8 & 7.3 & 45.7 \\
\hline Doti & Far-western hill & 63 & 31.3 & 85.3 & 27.8 & 6.2 & 37.6 \\
\hline Humla & Western mountain & 64 & 31.0 & 71.4 & 29.6 & 1.1 & 44.8 \\
\hline Jajarkot & Mid-western hill & 65 & 30.9 & 82.8 & 39.9 & 10.2 & 49.6 \\
\hline Siraha & Eastern terai & 66 & 25.7 & 68.4 & 45.1 & 26.9 & 48.2 \\
\hline Kapilbastu & Western terai & 67 & 25.6 & 68.0 & 33.9 & 27.2 & 41.3 \\
\hline Jumla & Western mountain & 68 & 22.4 & 73.0 & 34.3 & 4.5 & 51.9 \\
\hline Dhanusa & Central terai & 69 & 18.1 & 63.2 & 42.6 & 31.5 & 48.7 \\
\hline Parsa & Central terai & 70 & 15.5 & 65.2 & 40.6 & 31.4 & 50.3 \\
\hline Sarlahi & Central terai & 71 & 14.8 & 69.3 & 31.9 & 31.9 & 46.3 \\
\hline Rolpa & Mid-western hill & 72 & 14.1 & 77.7 & 24.5 & 8.4 & 42.6 \\
\hline Mahottari & Central terai & 73 & 11.7 & 71.6 & 35.8 & 33.0 & 50.1 \\
\hline Bara & Central terai & 74 & 11.5 & 68.9 & 38.5 & 31.0 & 52.5 \\
\hline Rautahat & Central terai & 75 & 4.2 & 73.2 & 30.8 & 34.1 & 53.3 \\
\hline
\end{tabular}

(Numbers in Red: low dependency ratio; Numbers in Green: relative low dependency ratio) 